\title{
O POEMA FORA DO LIVRO: JOAQUIM inojosa, Manuel Bandeira e Benedito MONTEIRO NO MODERNISMO PERNAMBUCANO
}

THE POEM OUTSIDE THE BOOK: JOAQUIM InOJOSA, MANUEL BANDEIRA AND BENEDITO MONTEIRO IN PERNAMBUCO'S MODERNISM

Leandro Pasini

Universidade Federal de São Paulo Guarulhos, SP - Brasil ORCID 0000-0001-6231-3860

\section{Resumo}

Este texto estuda a poesia modernista em Pernambuco na década de 1920, com foco na diversidade dos núcleos de produção cultural no Brasil. Propóe também um debate sobre o poema fora do livro, tendo em vista a relação desproporcional na história literária entre a forma do livro e os demais espaços do poema. Para isso, acompanha o impacto e o peso estético de "Bailado Rubro das Chamas", de Joaquim Inojosa, "Evocação do Recife", de Manuel Bandeira, além de "Knockout..." e "Poema da Bolsa", ambos de Benedito Monteiro. A relação desses textos com o seu contexto acentua e legitima a heterogeneidade dos ambientes em que o modernismo brasileiro se desenvolve e, com isso, complexifica tanto a noção de modernismo quanto a própria ideia de literatura brasileira.

Palavras-chave: modernismo pernambucano; poesia modernista; Joaquim Inojosa; Manuel Bandeira; Benedito Monteiro.

\begin{abstract}
This essay aims at studying the modernist poetry produced in Pernambuco in the 1920s, focusing on the diversity of centers of cultural production in Brazil. The paper also seeks to spark a debate about the poem outside the book, in view of the disproportional relationship between the book form and the other poetic spaces in literary history. To this aim, the paper examines the literary impact and the aesthetic value of Joaquim Inojosa's "Bailado Rubro das Chamas",
\end{abstract}

\section{Résumé}

Cet article se propose d'analyser la poésie moderniste à Pernambuco dans les années 1920, en se concentrant plus particulièrement sur la diversité des centres de production culturelle au Brésil. Étant donné le rapport disproportionné de l'histoire littéraire entre la forme du livre et les autres espaces du poème, on présente aussi un débat sur "le poème en dehors du livre". À cet égard, on suit l'impact historique et la composition esthétique de "Bailado Rubro das Cha- 
Manuel Bandeira’s "Evocação do Recife", and Benedito Monteiro's "Knockout..." and "Poema da Bolsa". The relationship between these texts and their context highlights and legitimizes the heterogeneity of the milieu in which Brazilian modernism evolved and, at the same time, affords a complex approach both to the notion of modernism and to that of Brazilian literature.

Keywords: modernism in pernambucano; modernist poetry; Joaquim Inojosa; Manuel Bandeira; Benedito Monteiro. mas", de Joaquim Inojosa; "Evocação do Recife", de Manuel Bandeira; et "Knockout ..." et "Poema da Bolsa", de Benedito Monteiro. La relation entre ces poèmes et le contexte socio-historique renforce et légitime l'hétérogénéité des milieux dans lesquels se développe le modernisme brésilien, ce qui complexifie à la fois la notion de modernisme et même l'idée de littérature brésilienne.

Mots-clés: modernisme à Pernambuco; poésie moderniste; Joaquim Inojosa; Manuel Bandeira; Benedito Monteiro.

All so old, so familiar - so new now William Carlos Williams, "The Wanderer"

Ao rememorar o roteiro de sua atuação em Recife, como principal divulgador da Semana de Arte Moderna de 1922, Joaquim Inojosa (1968, p. 42) se refere ao distanciamento que existia entre os diferentes núcleos de produção cultural do país: "O Brasil, sem avião e sem rádio, era um país de compartimentos estanques...”. Essa distância era sentida de modo diferente e recebia respostas distintas dependendo da perspectiva do observador. Para o modernista paulista Rubens Borba de Moraes (apud INOJOSA, 1969a, p. 373), esse afastamento possuía efeitos deletérios, que precisavam ser sanados pelo diálogo, como escreve em carta a Inojosa de 19/10/1924:

É necessário que no Brasil haja mais relaçôes intelectuais entre o Norte e o Sul. É o nosso único meio de estreitar os laços frágeis que unem esse imenso país, sem comunicaçôes e sem unidade real. O Brasil é um paradoxo. [...] não nos entendemos, porque não nos conhecemos.

No entanto, se por um lado a ideia de uma modernidade, cujo vetor iria do Sul para o Norte, despertava o entusiasmo de Inojosa, por outro ela recebia respostas defensivas que buscavam assegurar uma posição não subordinada a Pernambuco no cenário cultural brasileiro. 
Em suas memórias sobre a Recife da década de 1920, Souza Barros (1972, p. 152) aponta não somente para a posição de capital regional, de "centro de cultura e irradiação da área" nordestina, mas igualmente para a relativa independência intelectual de Recife em relação ao restante do País, pois possuía "[...] livrarias que se orgulhavam de acompanhar o vient-de-paraître de Paris e de outras Capitais europeias. Não recebia os livros e as revistas, as últimas informaçóes por intermédio do Rio mas diretamente". Nesse sentido, haveria um cosmopolitismo próprio que propiciava uma relativa autonomia cultural a Recife e o protegia da influência direta do Rio de Janeiro ou de São Paulo. Gilberto Freyre (apud D’ANDREA, 1992, p. 216), entretanto, acentua os aspectos negativos desse relativo deslocamento: "[...] eu era de uma parte do Brasil diferente das outras partes do Brasil. [...] de todas elas, talvez, a mais obscura, a mais submersa, a mais fora de foco". Dessa perspectiva decorre o esforço de Freyre não apenas para revalorizar e reintegrar Pernambuco entre as principais regióes do país, mas também para criar uma interpretação do Brasil baseada na experiência histórico-social do Nordeste, particularmente de Pernambuco. Contudo, a intenção deste ensaio não é analisar a grande realização de Freyre em Casa Grande \& Senzala (1933), mas sim o ambiente cultural do Recife da década de 1920, momento em que o peso da defesa do regionalismo feita por Freyre foi decisivo. O ponto de partida desta análise, então, acompanha de certa forma o ponto de partida do próprio Freyre (apud D'ANDREA, 1992, p. 216), a seu modo amplamente compartilhado, como vimos nos depoimentos anteriores: "O Brasil não era um todo monolítico, o Brasil era regionalmente diversificado".

O fato de o modernismo ter o seu início simbólico não na Capital Federal mas na província, em São Paulo, tornava evidente e dava maior relevância à diversidade de núcleos de produção cultural do Brasil. Desse modo, a difusão nacional do modernismo acentua e legitima a heterogeneidade dos ambientes em que ele se desenvolve e, com isso, por um lado complexifica a noçáo de modernismo, por outro a própria noção de literatura brasileira. $\mathrm{O}$ caso de Pernambuco se destaca nessa perspectiva porque, além da forte marca regionalista que o caracteriza, ele também evidencia a tensa relação entre grupos que compóem o modernismo, tendo em vista que é da simultaneida- 
de de três vertentes que se produz a dinâmica local do movimento: o "futurismo" de Joaquim Inojosa, a mistura difusa de localismo e experimentação formal da Revista do Norte (1923-1926), e o regionalismo programático de Gilberto Freyre. ${ }^{1}$ Contudo, se essa ramificação em pequenos grupos mostra as arestas, os desencontros e os desentendimentos dentro do modernismo, ela também cria um solo comum estético e social de um conjunto de obras contemporâneas e contraditoriamente entrelaçadas.

Pensando especificamente na história poética do modernismo em Pernambuco, um tema que surge é o do veículo material em que o poema se integra. Nesse contexto, é decisiva a presença de Ascenso Ferreira, coroada pelo fato de ele ter publicado um livro de poemas, levando assim à conclusão de que Catimbó (1927), justificaria a inserção de Pernambuco (e por consequência do Nordeste) na história do modernismo brasileiro (AZEVEDO, 1986, p. 186; INOJOSA, 1969a, p. iii; BARROS, 1972, p. 170). Com efeito, Ascenso tem contato com Inojosa, adere ao modernismo após a visita de Guilherme de Almeida a Pernambuco (1925), lê poemas no $1^{\circ}$ Congresso Regionalista do Nordeste (1926), corresponde-se com Mário de Andrade e publica o seu livro pela editora da Revista do Norte. Nesse sentido, ele é a figura que aglutina os diversos setores da intelectualidade pernambucana. Contudo, a ênfase excessiva na forma do livro publicado simplifica a dinâmica do processo literário e corre o risco de ofuscar as articulaçóes singulares do modernismo em Recife. Joaquim Inojosa, Austro-Costa, Joaquim Cardozo, Benedito Monteiro, Manuel Bandeira e o próprio Gilberto Freyre tiveram uma produção poética relevante nesse momento, publicada em jornais, revistas, ediçăo comemorativa, ou divulgada por correspondência. No dizer de Souza Barros (1972, p. 176), "à época, a imprensa, como divulgação, centralizava um poder muito maior que hoje”. Por isso, é preciso tentar equilibrar o prestígio do livro em relação aos demais espaços do poema, tendo em mente as diferentes formas de publicação

1 Note-se que é o memorialismo dessas três vertentes que constitui as principais linhas narrativas do movimento modernista em Pernambuco: Inojosa (1968, 1969a, 1969b), Souza Barros (1972) e Freyre (1996). Azevedo (1986) procura equilibrar em sua narrativa historiográfica essas três tendências, buscando sanar enganos propositais e, sobretudo, omissões (p. 11). Em proporções menores, há igualmente depoimentos de Joaquim Cardozo (apud BARROS, 1972) e Ascenso Ferreira (apud CAVALHEIRO, 1944). 
e divulgação do poema fora do livro, bem como o seu peso estético e histórico-literário.

\section{A poética ardente de Inojosa e suas contradições}

Joaquim Inojosa, que inicia uma ruidosa e confusa campanha a favor do modernismo do Sul, publica, entre 1923 e 1926, uma série de prosas poéticas entremeadas de versos nas revistas $A$ Pilhéria, Mauriceia, Rua Nova, Revista de Pernambuco, Era Nova, A Rua e Vida Feminina, bem como no Jornal do Comercio. ${ }^{2}$ Em certa medida, essa produção lembra os traços do Inojosa polemista, sempre inclinado ao discurso inflamado e à pregaçáo, com frequência indiferente aos elementos técnicos e à concretude e singularidade das obras modernistas. Suas prosas poéticas apegam-se sistematicamente a exterioridades de imagens, de cores e de danças, em um processo que poderia ser descrito a partir de um trecho de seu poema "Carnavália": "num desequilíbrio quase rítmico de roda sem eixo" (INOJOSA, 1969a, p. 214). Pode-se, no entanto, pensar em vários de seus poemas como expressão daquela categoria que Bandeira chamou de "ruim esquisito", em formulaçôes como "de tấo azul muita coisa desaparece" (1969a, p. 206) ou "essa mulher despertou em mim um bailado de emoçôes verdes" (1969a, p. 229).

Parece-me que o seu melhor poema é "Bailado Rubro das Chamas", publicado originalmente na Revista de Pernambuco, ano III, fev. de 1926, pois nele o tom inflamado de sua escrita encontra um tema afinado ao seu gesto, o que, por um lado, lhe confere maior coerência estética e, por outro, ressalta os seus defeitos. Futurista em seu propósito de destruir o passado, "as chamas começam a devorar o edifício antigo": agitadas ao jazz-band infernal do vento, destroem relíquias como retratos, santuário e um velho piano. $\mathrm{O}$ início do poema é agitado, com a onomatopeia dos sinos "Bão!... Bão!... Bão!... Bão!...", a inquietação da cidade, a pressa dos bombeiros. A esse trecho inicial de dez versos segue-se a descrição das chamas tomando o edifício. É aqui que o poema se ressente da falta de um cuidado formal maior. A inflamação discursiva, tâo própria de Inojosa, que poderia ter neste

2 Todos reproduzidos, com suas respectivas referências em Inojosa (1969a). 
poema encontrado a sua forma poética correspondente, esquece de destruir algumas expressóes pouco modernas: as chamas, além de ágeis e nervosas, são "alígeras", "irosas", palavras que destoam um pouco do aspecto febril do texto. Contudo, os descompassos do léxico seriam pouco importantes se eles não antecipassem a ruína do próprio poema no verso final: "[...] o velho piano da saudade do edifício da vida reduzido a cinzas ao bailado rubro do ideal!...”. Uma frase longa, abstrata, entre reticências e exclamação, funcionando como um tipo de chave de ouro em que a destruição febril se acalma na bem edificada e empoeirada contraposição entre a melancolia da saudade e a pungência do ideal.

O sentido estético e histórico da destruição do passado perde o pé e se apega a fórmulas de sabedoria muito pouco novas, o que caracteriza a militância um tanto fora do eixo de Inojosa. À atuação de Inojosa em favor de um modernismo febrilmente idealizado e mal digerido, contrapunham-se duas forças mais apegadas às tradiçóes locais, a da Revista do Norte, que veremos em momento posterior deste texto, e o programa regionalista de Gilberto Freyre. Este último será abordado aqui na medida em que faz parte da discussão proposta, isto é, da poesia modernista em Recife, o que, se não diminui a importância da sua figura, enfatiza apenas um momento específico de sua participação na história do modernismo pernambucano. Para tanto, é importante notar a posição de Freyre diante da ideia de modernidade. Tendo em mente que Freyre tinha estudado nos Estados Unidos antes de voltar para Recife em 1923, Souza Barros, enquanto elaborava as suas memórias, lhe envia um questionário em que consta a seguinte pergunta: "Por que tendo estudado num país que já realizara o seu desenvolvimento industrial deu apenas ênfase a um processo de renovação cultural através da volta ao regionalismo tradicionalista?" (BARROS, 1972, p. 75-76). A pergunta é objetiva e se relaciona com o processo de modernizaçáo técnica e cultural do mundo de então. A resposta de Freyre indica o processo pelo qual ele mesmo se modernizava: "Porque atribuo importância ao cultural que norteia o tecnológico e o econômico" (apud BARROS, 1972, p. 305). A importância dada à cultura, nesse contexto, não se vincula 
a uma noção de tradicionalismo; ao contrário, adere aos avanços da Antropologia que Freyre aprendeu com Franz Boas em Columbia. ${ }^{3}$

Nesse sentido, a concepçáo da originalidade regional como criação cultural singular a ser entendida e estudada na sua dimensão concreta não se limita a uma expressão de saudosismo; ao contrário, ela também renova no contexto brasileiro a antropologia cultural que Boas levava a cabo nos Estados Unidos. Aqui é possível traçar um paralelo estrutural entre o modernismo de Sáo Paulo e o regionalismo de Gilberto Freyre. O grupo de Klaxon buscava atualizar a expressão artística brasileira a partir da diretriz da vanguarda parisiense dos anos 1910, enquanto Freyre buscava atualizar o estudo da originalidade da regiáo nordestina a partir da modernidade de matriz estadunidense. Nos dois pontos, a novidade recebida de um centro de produção se desdobrava na procura atualizada e modernizada de uma originalidade local que se expandia e englobava a ideia de nação. Assim, para além do confronto regional (que também existia), o que interessa aqui é o paralelismo dos processos, com suas divergências e convergências.

O modo inicial com que Freyre avalia o movimento modernista pode ser observado no artigo "A Propósito de Guilherme de Almeida”, publicado em 15/11/1925, no Diário de Pernambuco, quando este pronuncia a sua conferência "A Revelação do Brasil pela Poesia Moderna” em Recife:

O sr. Guilherme de Almeida não distingue a tradição que se vive da tradição que se cultiva a discurso e a fraque e a hino nacional e a vivas à República. Ele não distingue o regionalismo à Jeca Tatu, caricaturesco e arrevezado, do regionalismo que é apenas uma forma mais direta, mais sincera, mais prática, mais viva de ser brasileiro (apud INOJOSA, 1968, p. 151).

Segundo Freyre, então, o nacionalismo cultural modernista não saberia distinguir o pitoresco do tradicional, o folclórico visto como exotismo do que é a vida ao mesmo tempo imediata e secular de quem perpetua a originalidade regional da vida brasileira. Ambos,

3 No prefácio à $1^{\text {a }}$ edição de Casa Grande \& Senzala, Freyre diz que Boas the ensinou a diferença entre raça e cultura, e que "Neste critério de diferenciação fundamental entre raça e cultura assenta todo o plano deste ensaio" (2000, p. 45). 
contudo, buscam um ideal de "naturalidade" nacional, só que para Freyre ela já existe, precisa apenas ser cultivada e expandida, enquanto para o modernismo paulista ela precisa ser criada.

A militância de Gilberto Freyre seguia, assim, um caminho de valorização consciente de todos os aspectos tidos como originais no ambiente pernambucano que, por sua vez, seria o resultado original dos séculos de colonização e mestiçagem cultural, e que encontraria na culinária o seu ponto de realização mais perfeito. Do ponto de vista literário, a principal realização de Freyre nos anos 1920 foi a incorporação poética de Manuel Bandeira ao contexto recifense, ao pedir-lhe um poema memorialista sobre a Recife da infância do poeta para o Livro do Nordeste (1925), edição comemorativa dos cem anos do Diário de Pernambuco. Manuel Bandeira, por sua vez, percebia a atuação de Freyre em relação às tradiçóes regionais como algo mais concreto e produtivo do que a militância abstrata de Inojosa. Em carta a Drummond de 03/02/1926, Bandeira fala sobre a sua relação com a cena cultural pernambucana, tendo como referência a sua principal contribuição para ela, o poema "Evocação do Recife":

Se você não fosse pau e tivesse querido ficar pra dormir no dia em que jantou aqui com uma pressa táo grande que nem o vinho acabou de beber, eu teria lido pra você (era meu intento) a "Evocação do Recife", coisa que fiz por pedido e sugestáo do Gilberto Freyre. (...) Gilberto Freyre é um rapaz de 24 anos, creio. Informaram-me que já esteve 4 anos nos Estados Unidos. É inteligentíssimo. Não é modernista mas gosta muito de nós. Está fazendo no Norte uma campanha em favor das boas tradiçóes brasileiras. Parece que foi ele quem descobriu aquele desenhista meu xará e o Joaquim Cardozo que também é pintor. Esses três passadistas me parecem muitíssimo mais interessantes do que os "modernistas" de lá, todos muito fraquinhos (BANDEIRA, 1958, p. 1390-1391).

O Centro Regionalista do Nordeste, de que Freyre era o inspirador e a principal figura teórica, não possuía um programa literário (AZEVEDO, 1986, p. 144). Entretanto, Gilberto Freyre demonstrou, por um lado, um ideal de escrita jornalística fluida, clara e direta, sem ornamentação ou retórica desnecessária, por outro conhecimento 
in loco da moderna literatura anglo-americana, que teria inspirado o poema "Bahia de todos os Santos e todos os Pecados", publicado em 1926 na Revista do Norte. ${ }^{4}$ Contudo, o "grande poema do Recife" para Freyre, do qual ele foi o inspirador e se considera de certa forma coautor, é "Evocação do Recife", 5 de que passo a acompanhar a gênese e a função na dinâmica local do modernismo pernambucano.

\section{"Evocação do Recife": os caminhos de um poema}

Antes de ser publicado no representativo Livro do Nordeste, "Evocação do Recife" teve um percurso que evidencia, ao mesmo tempo, os diferentes caminhos e os diversos espaços de um poema. $\mathrm{O}$ contato de Gilberto Freyre com Manuel Bandeira começa por carta, quando este lhe envia elogios pelos artigos sobre a cozinha pernambucana, publicados no Diário de Pernambuco, ao que Freyre responde com o pedido de um poema sobre Recife (HOMENAGEM, 1936, p. 87-88). Portanto, o percurso inicial do poema começa pela correspondência, apela ao memorialismo do poeta e se realiza em um tipo de almanaque. Desse modo, "Evocação do Recife" atua dentro do modernismo mais como um poema solto (1925) no contexto pernambucano do que dentro do livro Libertinagem (1930) no contexto carioca. No entanto, ainda aqui o modernismo pernambucano se constitui pela confluência entre Freyre e Inojosa, pois o despertar poético-memorialístico de Bandeira é rastreável na correspondência deste com Inojosa. Em carta de 13/03/1925, Bandeira escreve: "Pernambuco, donde sou, mas onde vivi apenas 4 ou 5 anos, 3 deles porém na quadra em que as impressóes recebidas são indeléveis, dos 6 aos 9 anos. A minha rua da União! O sertãozinho de Caxangá! Monteiro! O engenho do Cabo!”. Inojosa publica essa carta em $A$

4 "É evidente que, de modo desajeitado, foi um poema imagista que procurei escrever ao evocar a Bahia como cidade 'de todos os santos e de todos os pecados"” (FREYRE. "Amy Lowell: uma revolucionária de Boston” apud DIAS, 2007, p. 390).

5 "Ninguém pode hoje falar de Manuel Bandeira sem ter lido esse poema; nem falar do Recife, de sua história - de sua história no sentido mais lógico, e até no mais cronológico e mais convencional - sem saber quase de cor a 'Evocaçáo'. // É o grande poema do Recife" (apud HOMENAGEM, 1936, p. 89). Quase 50 anos depois, Freyre reitera a sua participação no poema: "o poema de Manuel Bandeira - 'Evocação do Recife' - é de forma modernista, valorizando, entretanto, valores regionais e tradicionais. Uma inspiraçáo minha'” (apud D'ANDREA, 1992, p. 42). 
Pilheria, e Bandeira responde em 28/04/1925 "encalistrado" pela indiscrição de Inojosa, mas Ribeiro Couto o tranquiliza dizendo que a carta tinha "o encanto de minha saudade pelo Recife" (INOJOSA, 1969a, p. 355-356). ${ }^{6}$

Assim, é possível fazer um tipo de arqueologia do percurso externo de "Evocação do Recife", que pode, por sua vez, ser complementado pela análise de seu percurso interno. A forma do poema de Bandeira se vincula à questáo do nacionalismo literário em poesia. O "Manifesto da Poesia Pau-Brasil" (1924), de Oswald de Andrade, que defendia uma forma poética simultaneamente experimental e conscientemente brasileira é complementada pelas pesquisas estéticas de Mário de Andrade. Este, em poemas como "Carnaval Carioca" (1923) e "Noturno de Belo Horizonte" (1924), compóe uma forma longa, que apreende um percurso por uma parte do território brasileiro, faz a incorporação poética da língua falada, das impressôes sensíveis do ambiente e das efusóes do sujeito lírico em contato com a diversidade da matéria nacional. Manuel Bandeira recebe com entusiasmo esses poemas de Mário, principalmente o "Noturno de Belo Horizonte", sobre o qual ele escreve em carta de 02/05/1925: "Você descobriu o grande poema brasileiro. Todas essas coisas da terra que você diz táo amendoim-torradamente [...], eu sufocava de dizer. Não sabia como, Você achou como" (MORAES, 2000, p. 195). Bandeira já havia abordado essa questão com a mesma conclusão em carta a Drummond de 21/10/1924 sobre o problema do nacionalismo na arte brasileira: "[...] creio que no fundo estấo todos de acordo e o problema é enquadrar, situar a vida nacional no ambiente universal. [...] O Mário de Andrade [...] parece ter resolvido o problema nos seus últimos poemas, sobretudo no 'Noturno de Belo Horizonte" (BANDEIRA, 1998, p. 583).7

Antes de proceder a uma leitura de "Evocaçáo do Recife", é preciso notar a heterogeneidade dos materiais de que se constitui

6 Algo da atmosfera do poema já despontava em carta de 21/10/1924 a Drummond: "sou provinciano também - um provinciano, de Pernambuco, que vive desde menino na corte, com uma burra saudade dos engenhos" (BANDEIRA, 1998, p.584).

7 Sobre a relação poética de Mário e Bandeira, leia-se ainda essa passagem do mesmo Bandeira em carta de 26 de junho de 1925: "Acho mesmo que convém que nos imitemos, que nos plagiemos, que nos influenciemos para firmar cada vez mais essa característica racial que já é patente e bem definida” (MORAES, 2000, p. 219). 
uma historiografia materialista da literatura. Jornal, correspondência, almanaque (edição comemorativa), revista, entre outros, compóem um emaranhado de confluências em diversos níveis que marcam a diversidade de manifestaçóes modernistas. Os espaços do poema são numerosos e configuram a dinâmica literária de modo paralelo à forma do livro, por vezes demarcando o espaço sem a presença do livro, como é o momento histórico do modernismo pernambucano, que estamos acompanhando. Ao resumir, então, a história da "Evocação do Recife", temos o seguinte: após a leitura de textos de jornal de Freyre, Bandeira e ele iniciam uma correspondência e, por meio dela, Freyre pede um poema; o poema vai ter como base o nacionalismo poético-experimental de Mário e o memorialismo da infância recifense de Bandeira. Essa relação entre nacionalismo poético e memorialismo provinciano configura o poema, que é publicado em uma edição comemorativa. Assim, a despeito de diferenças declaradas entre regionalismo e modernismo, provincianismo e cosmopolitismo, é em uma teia de diálogos composta de diversos elementos que se elabora a síntese poética de Bandeira, em que convergem essas perspectivas diferentes. Podemos adiantar que, nesse ponto, a linguagem poética modernista ao mesmo tempo se consolida e, de certa forma, se pacifica como a língua geral dos setores atualizados esteticamente e/ ou modernizantes das oligarquias locais brasileiras.

"Evocação do Recife" começa com a evocação do nome da cidade seguido por uma série de negativas:

Recife

Não a Veneza americana

Não a Mauritssatd dos armadores das Índias Ocidentais

Não a Recife dos Mascates

Nem mesmo o Recife que eu aprendi a amar depois Recife das revoluçóes libertárias

Mas o Recife sem história nem literatura

Recife sem mais nada

Recife da minha infância

Com um verso solto, cujo ritmo acompanha a forma do memorialismo poético, Bandeira busca um Recife sem adjetivo pré- 
vio, despojado de toda monumentalidade e, com isso, aumentado em sua poeticidade modernista. Depois desse despojamento, o poema se compóe de versos longos como a memória que se perde no tempo (a exemplo da estrofe seguinte à citada), entradas abruptas ("De repente/ nos longes da noite", v. 22-23, ou "Cheia! As cheias! Barro boi morto árvores destroços redomoinho sumiu”, v. 47), travessóes, palavras que ocupam de forma livre o espaço da página (como "um sino", v. 24, no fim de uma linha que não tem nenhuma outra palavra), contraposição da liberdade da língua falada à prisão artificial da métrica e da "sintaxe lusíada” (v. 62-69), entre outros recursos expressivos. No geral, o tempo verbal dominante no poema é o pretérito imperfeito, apropriado ao passado cuja extinção cronológica se prolonga na temporalidade da memória. O pretérito perfeito foi usado em alguns poucos momentos em que a singularidade e a força epifânica da experiência impediam a sua continuidade no tempo ou repetição, como em: "Um dia eu vi uma moça nuinha no banho/Fiquei parado com o coração batendo/ Ela se riu/Foi o meu primeiro alumbramento" (v. 42-46). Os únicos verbos no presente do indicativo se referem ao mau uso da língua portuguesa pelos contemporâneos no momento de enunciaçáo do poema (v. 65-68).

O tempo de "Evocação do Recife", então, é "sem história nem literatura", isto é, sem as convençôes da história oficial, sem as convençóes da literatura oficial, convergindo em um espaço em que infância, memória, verso livre, língua falada, gestualidade e ambiente social naturalizados pela visão desarmada da criança constituem um momento de síntese dentro da poesia modernista em Pernambuco e no Brasil como um todo. Contudo, é justamente no entroncamento do ambiente a-histórico da memória infantil com o tempo histórico socialmente marcado que se situa o ponto mais contraditório do poema. D'Andrea nota que "Evocação do Recife" "revela como a memória poética e familiar pode ser contaminada pelo solo histórico dessa banda nordestina e, dessa maneira, realimentar determinada tradição” (D’ANDREA, 1992, p. 45). Estaria nessa convergência do tempo morto da memória ("Meu avô morto/Recife morto...", v. 78-79) com o tempo presente da estrutura social de Pernambuco a ambivalência de classe do poema, em que "[...] a marca idílica do Recife patriarcal [...] restabelece o tempo simbólico da hegemonia 
tradicional" (D'ANDREA, 1992, p. 45), e, nesse sentido, o lirismo de Bandeira afiançaria a interpretaçáo do Brasil de Freyre, em que as relaçóes afetivas não só atenuariam o escravismo e suas consequências, como comporiam por meio desse mesmo mundo escravocrata sem culpa a primeira civilização original do continente americano, isso tudo com sinal positivo.

O núcleo contraditório do poema se encontra nas diferentes temporalidades de Bandeira e de Gilberto Freyre. Bandeira recuperou o lirismo do tempo socialmente extinto captado pela memória, libertado pela linguagem popular, pelo psicologismo da poesia modernista e pelo poema de imersão itinerante na matéria brasileira de Mário de Andrade. O que dá força poética à "Evocação do Recife" é o fato de que ela diz respeito a um tempo que não existe mais, cuja expressividade se deve ao lampejo fugaz de uma matéria extinta, para a qual o modernismo confere um lirismo de libertação. Contudo, a permanência histórica do patriarcado, a presença objetiva da lei da "casa do avô", senão como dominaçáo efetiva, como perspectiva de interpretação histórica, como apologia patrimonial e como nostalgia cultural geram uma infiltração gilbertofreyriana no poema, a despeito ou não da concepção de Bandeira. Profundamente ambivalente, "Evocação do Recife" estabelece, entretanto, a aliança poética entre o regionalismo de Gilberto Freyre e o nacionalismo de Mário de Andrade, ampliando nesse sentido o sistema literário modernista, conferindo-lhe a inflexão de Gilberto Freyre que, por sua vez, encontra a solução poética de sua militância regionalista. A poesia modernista se expande, desse modo, como língua geral dos núcleos de produção cultural do Brasil, que se modifica de acordo com a originalidade e as contradiçóes de cada um desses núcleos, além de manter os laços visíveis de um sistema poético com uma dinâmica própria.

\section{Benedito Monteiro: o extravio de um poeta}

Paralelo à disputa entre Joaquim Inojosa e Gilberto Freyre, havia o grupo da Revista do Norte (1923-1926), editada por José Maria Albuquerque Mello, de periodicidade errática e sem um programa definido. Embora a revista se propusesse à defesa dos valores tradicionais e locais, afinando-se, assim, ao regionalismo de Gilberto 
Freyre (AZEVEDO, 1996, p. 119), ela também abria espaço para manifestaçóes poéticas mais livres, como as de seus dois principais poetas, Joaquim Cardozo e Benedito Monteiro. Do ponto de vista do poema fora do livro, é importante destacar a presença de ambos e, sobretudo, daquele que náo voltou a publicar os seus poemas, devido à sua morte precoce: Benedito Monteiro. Dado o caráter difuso, entre tradicionalista e moderno, da Revista do Norte, ela se tornou o espaço em Recife de uma boemia esteticamente criativa e descompromissada, para a qual o modernismo náo se transformou em programa, mas alcançou uma expressão original, que de certa forma reconfigura o modo de se conceber tanto o modernismo pernambucano em particular quanto o modernismo brasileiro de um modo geral.

A perspectiva pela qual pretendo abordar aqui dois dos poemas de Benedito Monteiro na Revista do Norte, "Knockout..." (publicado no ano 2, n. 5, out. 1924) e "Poema da Bolsa" (ano 3, n. 1 , out. 1925$)^{8}$ é a de um momento em que uma modernidade difusa e não ortodoxa (nem programática) atinge um ponto de originalidade inesperado (e efêmero) no quadro mais geral do sistema poético-literário modernista da década de 1920. A primeira característica que singulariza o poeta é o seu apego ao Recife moderno, isto é, não à modernidade abstrata de Inojosa nem à modernidade antropológica de Freyre, mas à modernização empírica da cidade, como nos informa Souza Barros: "O Recife da década [de 1920] não era mais, assim, o Recife do açúcar; ele era talvez o Recife do empório comercial [...] e da rede ferroviária [...] do novo porto" (BARROS, 1972, p. 79). Além disso, Benedito chegou a trabalhar em um escritório comercial e costumava frequentar a Bolsa de Valores, onde pôde acompanhar a lógica financeira dos números e dos valores, dos câmbios e das moedas, o

8 Embora eu não tenha tido acesso a uma coleção completa da Revista do Norte, há a seguinte descrição de Azevedo (1996) sobre a presença de Benedito Monteiro na revista: "Suas colaboraçóes - seis textos em prosa e cinco poemas. [...] Nos textos críticos deve ser ressaltada a modernidade do seu estilo, feito de frases curtas e incisivas, usando imagens originais, tudo aliado a uma postura irreverente e crítica. [...] Nos poemas, Benedito Monteiro passa do soneto à experimentaçáo formal, na linha preconizada pelo modernismo do primeiro momento" (p. 116). Cumpre ressaltar que Benedito Monteiro foi reconstruído historicamente pelo trabalho de pesquisa e memorialismo de Souza Barros (1972), cujo capítulo a respeito do poeta (p. 263-281) é a principal fonte de consulta. Benedito Monteiro morre em 18/07/1925. 
que lhe teria inspirado um desaparecido "Poema dos Números" ou "Poema Numérico", de que trataremos mais adiante.

A essa dimensão moderna e mercantil, que aparece em alguns de seus poemas, some-se o dinamismo do boêmio aglutinador do grupo, que ajudou a compor a cena literária heterogênea que Souza Barros denomina "cenáculo da Lafayette". Foi Benedito Monteiro que levou Souza Barros à esquina da Lafayette, onde este conheceu Joaquim Cardozo, que por sua vez "constituía o centro das reuniôes" (BARROS, 1972, p. 209). Nesse sentido, Benedito atuava como aglutinador, e Cardozo como centralizador do grupo (BARROS, 1972, p. 223). O próprio Joaquim Cardozo, entretanto, fora trazido por Benedito, que, além disso, exerceu grande influência sobre Ascenso Ferreira (apud CAVALHEIRO, 1944, p. 84). Benedito é descrito como dotado de constante inquietação, poder comunicativo e gosto pela provocação e pelo desafio, o que compóe o perfil de um espírito boêmio e experimental, lúdico e vitalista.

Joaquim Cardozo viu nessas características o poeta "que melhor compreendeu, no Recife, o sentido da poesia de 22" (apud BARROS, 1972, p. 147). Essa afirmação levanta a questão sobre o modo como Cardozo e Benedito Monteiro receberam e interpretaram a poesia modernista de São Paulo e do Rio de Janeiro. Cardozo, que introduz a poesia de Bandeira no Livro do Nordeste, conta que teve contato com o modernismo no Rio em 1923 (apud BARROS, 1972, p. 139), e que Benedito tomou conhecimento do movimento pela Revista do Brasil no mesmo ano:

Em 1923, o movimento da Semana de Arte Moderna já estava divulgado pela Revista do Brasil, e, através dela, Benedito, que já tinha inclinação modernista, começou a fazer os seus versos e a declarar, bebendo bitter e fumando cachimbo, versos de Mário e Oswald de Andrade, de Sérgio Milliet e Luís Aranha; isto, de mistura com versos de Raimundo Correia [...], versos, assim, que no parnasianismo já continham o germe da poesia nova” (BANDEIRA apud BARROS, 1972, p. 139).

Ainda que o trecho apresente algumas falhas históricas, como apontar a poesia de Oswald em 1923 (ele começa a publicar 
poemas de Pau-Brasil em 1924) e a presença de Luís Aranha na Revista do Brasil (Luís Aranha só publica em Klaxon), ele vale por evocar a presença da poesia modernista em Benedito e, principalmente, o nome de Luís Aranha, com quem o poeta pernambucano parece ter diversas afinidades, como se pode ler em "Knockout...".

Knockout. Forças estranhas.

Sacos de 75 kilos. 6 1/4 a 6 7/8.

O califa... A besta...

No conjunto das impressóes se abismam.

5 O movimento retrógrado. A self-induction.

A reação. $\mathrm{O}$ peso morto. A carne frigorificada.

O pulsar dos motores dos hidroavióes.

Os carburadores. As carretas. Os cilindros.

O lirismo dos cilindros em estrela.

$10 \mathrm{O}$ zum-zum longínquo das hélices.

6000 rotaçóes por minuto.

As grandes linhas internacionais.

Paris. Dakar. Buenos Aires. Punta Arenas...

Seattle. As Aleutas.

15 Raid à volta do mundo.

Integrei-me, explicitei-me

Eu era uma função implícita.

Respiro os ambientes de petróleo.

Bebo as paisagens de 100 milhôes de hectares.

20 As retinas veem os focos de 1000 kilowatts.

As retinas veem a música silenciosa das catástrofes.

Sem título, o poema começa com a força do choque presente na primeira palavra "Knockout". ' As referências geográficas e sobretudo tecnológicas são profusas, e não poderei aqui proceder a uma exegese detalhada dos versos. Contudo, quero chamar a atenção a dois elementos constitutivos do poema: a sua lógica formal e a sua impregnação de números. O poeta aceita de modo enfático as sugestóes da modernidade tecnológica e compóe os seus versos com ritmo

9 Souza Barros (1978, p. 273) acrescenta ao poema o título "10 - 1000 - 1000000". 
acelerado, pondo ênfase na simultaneidade das sensaçóes acumuladas pela sequência de nomes. É justamente desse elemento, no verso livre composto prioritariamente de substantivos, que o poema tira o seu elemento rítmico. Embora o terceiro verso: "O califa... A besta..." evoque o verso harmônico de Mário de Andrade em Pauliceia desvairada, Benedito Monteiro está mais próximo das palavras em liberdade do futurismo com sua ênfase nos substantivos, na onomatopeia, nos termos técnicos e nos números. Note-se que os verbos aparecem pouco no poema: depois do segundo verso, eles só surgem nos últimos cinco (v. 16-21). Ao contrário do "Bailado Rubro das Chamas", de Inojosa, Benedito funde o tema da modernidade tecnológica com as técnicas modernistas da poesia levadas ao extremo. É nesse sentido que o poeta, à maneira de Luís Aranha, em "Aeroplano" (Klaxon, n. 2), mas com inflexáo própria, se identifica à força dinâmica da máquina, que, levada ao ponto máximo de rendimento, conduz à catástrofe.

Benedito tira proveito próprio dessa poética da máquina em uma imagem como "O lirismo dos cilindros em estrela", em que o motor do aviáo envolto por cilindros se apresenta ao poeta com a evocação lírica de uma estrela. Contudo, a principal originalidade compositiva do poeta está no aproveitamento que ele faz da matemática ao longo dos versos. Não apenas os números e sua função tecnológica e econômica comparecem em "Knockout..." (v. 2, 11, 19, 20), mas a própria presença do eu lírico evoca a lógica do cálculo, no qual, até onde posso entender, a "função implícita" é algo que se deduz de uma expressão matemática, isto é, que está presente na equação sem que seja nomeado, enquanto "integrar-se" não significa "fazer parte de", mas é uma espécie de soma de valores de uma função. Embora seja difícil precisar em que medida a matemática está em estado puro nos versos e em que medida ela é metafórica, pode-se concluir que os números e sua lógica operam no poema como um tipo de ironia própria em relaçáo à linguagem verbal, gerando uma contradição poética consciente, que confere uma inquietante originalidade ao poema de Benedito Monteiro.

Se em "Knockout..." o poeta dá volta ao mundo pelo pulsar de motores e hélices, no "Poema da Bolsa" o foco é a modernidade financeira da Bolsa de Valores: 


\section{O POEMA DA BOLSA}

A Bolsa de mercadorias. As oscilaçóes do mercado.

A curva logarítmica da queda da arroba do açúcar.

Os magnatas sentados pelas mesas esperando o pregão dos corretores.

Os especuladores baixistas esperando vender a prazo para recomprar com lucro.

5 Os especuladores altistas esperando comprar a três meses para revender depois.

Os negócios firmes altamente perigosos.

Os corretores, correntes elétricas entre as diferenças de potencial da oferta e da procura.

Ah! A aristocracia dos senhores de engenho, açúcar de 2 cruzados.

A democracia dos fornecedores de cana e donos de banguês, açúcar $11 \$ 600$

$10-11$ horas.

O pregáo.

- Vendo 4000 sacos de cristal a $12 \$ 900$ para a entrega em Dezembro.

- Compro a $12 \$ 000$ réis.

E a batalha incruenta está travada com derramamento do sangue loiro das

esterlinas!

Ainda que o poema náo a nomeie, provavelmente estamos na Bolsa do Recife, acompanhando o preço do açúcar e a sua correspondente movimentação social. No entanto, os números da riqueza (e da pobreza) do açúcar não apresentam o dinamismo de "Knockout...". Ao contrário, os versos longos e muito longos, descritivos e quase burocráticos compóem um ambiente modorrento, habitado por tipos sociais como especuladores, corretores e senhores de engenho. O poema é dividido claramente pelo cenário antes e depois da abertura do pregáo e da movimentaçáo do dinheiro, quando os versos ficam mais curtos, com travessóes e valores. Antes do pregão, domina a inatividade, todos estão sentados, esperando; e energia, quando há, é a do cálculo, como a dos corretores: "correntes elétricas entre as diferenças de potencial da oferta e da procura” (v. 7). A aristocracia dos senhores de engenho, que fundamenta a interpretação do Brasil de Gilberto Freyre e a infância de Bandeira em "Evocação do Recife", 
é posta diante da sua base econômica, da "curva logarítmica da queda da arroba do açúcar”. Nesse sentido, trata-se aqui de um grupo que é menos sujeito de uma história regional ou nacional do que objeto de um sujeito maior e mais dinâmico: o preço.

O poeta, então, não estrutura o seu poema a partir das características locais, como a cultura histórica, rural, urbana, senhorial etc. de Pernambuco; antes, é a própria produção material da ideia de local que sustenta o poema, isto é, os números que valorizam ou desvalorizam o produto regional. A aristocracia dos senhores de engenho é medida pelo seu valor no mercado internacional: "açúcar de 2 cruzados", afiando a observação socioeconômica pelo procedimento poético da justaposição. A poesia da modernidade cosmopolita descobre n'o "Poema da Bolsa" uma nova mediação: a transformação do açúcar em número e do número em câmbio. A metáfora literária se une à matemática para que o açúcar se torne o cruzado, que, por sua vez, se transformará em libra esterlina. Diante desse quadro, o poema se encerra com um tipo de verso de ouro, uma espécie de sopro épico caricato e, no entanto agudo, em que o "sangue loiro das esterlinas" sustenta com a sua sangria os conflitos e a cultura local, bem como o seu internacionalismo.

A poética modernista de absorção da modernidade técnica e de apreensão do dado brasileiro atinge nesses dois poemas outra dimensão, pois se configura a partir do elemento numérico, seja nas máquinas de "Knockout..." ou no mercado financeiro de "O Poema da Bolsa”.

\section{Conclusão: "Poema dos Números", ou "Poema Numérico"}

O poema fora do livro, conforme verificamos em "Bailado Rubro das Chamas", de Inojosa, "Evocação do Recife", de Bandeira, "Knockout..." e "Poema da Bolsa", de Benedito Monteiro, pode funcionar como um prisma, em que a linguagem poética de um movimento público e coletivo se estrutura e adquire originalidade. Assim, o poema fora do livro permite também recompor os fios soltos do modernismo brasileiro, caminhos que despontaram e náo foram levados a cabo, convivendo com outros projetos que se consolidaram, 
mas que deixaram um espaço aberto para repensar o movimento, a exemplo da relaçáo entre o que foi realizado e o que foi perdido.

No contexto pernambucano, temos um caso de perda que ilumina as possibilidades de interpretação do movimento. Souza Barros nos conta o seguinte: "Tomei conhecimento e talvez tivesse recebido cópia, do próprio Benedito, de um 'Poema Numérico' ou 'Poema dos Números', onde, baseado no seu gosto matemático, explorava as oscilaçóes cambiais, a subida e descida da moeda, o impacto da crise" (BARROS, 1972, p. 276). É difícil não pensar em como seria esse poema e de que modo ele se relacionaria com os dois poemas lidos aqui, ambos construídos com forte presença dos números. Contudo, a ausência desse poema não precisa necessariamente conduzir à melancolia de sua perda. Ao imaginar como ele seria, é possível ultrapassar as fronteiras locais e nacionais do modernismo e estabelecer formas imprevistas de conexôes com diversos modernismos. Assim, o inexistente "Poema dos Números", ou "Poema Numérico", evoca este outro, de um poeta igualmente fascinado pelos números, Velimir Khlebnikov, embora Benedito Monteiro os olhasse em seu funcionamento técnico e materialista, e o poeta russo pelas suas sugestóes de interpretação mística da história:

\section{NÚMEROS}

Eu vos contemplo, ó números!,

vestidos de animais, em suas peles,

as mãos sobre carvalhos destroçados.

Mostrais a uniâo entre o serpear

da espinha dorsal do universo e o bailado da balança.

Permitis a compreensão dos séculos, como os dentes numa breve gargalhada.

Meus olhos se arregalam intensamente.

Aprender o destino do Eu, se a unidade é seu dividendo. ${ }^{10}$

10 Tradução de Marco Lucchesi (KHLEBNIKOV, 1993). Reproduzo o original, publicado no almanaque Dokblaia Luna. Moscou, 1913: ЧИСЛА: Я всматриваюсь в вас, очисла,/И 


\section{Referências bibliográficas}

AZEVEDO, N. P. de. Modernismo e Regionalismo: os anos 20 em Pernambuco. João Pessoa: Edufpb, 1986.

BANDEIRA, M. Poesia e prosa. Rio de Janeiro: Nova Aguilar, 1958. v. 2. . Seleta de prosa. Rio de Janeiro: Nova Fronteira, 1998.

BARROS, S. A década 20 em Pernambuco. Rio de Janeiro: [s./n.], 1972.

CAVAlHEIRO, E. Testamento de uma geraçâo. Porto Alegre: Livraria do Globo, 1944.

D'ANDREA. A tradição re(des)coberta: o pensamento de Gilberto Freyre no contexto das manifestaçôes culturais e/ou literárias nordestinas. Campinas: Edunicamp, 1992.

DIAS, S. M. V. Cartas provincianas: correspondência entre Gilberto Freyre e Manuel Bandeira. 2007. Tese (Doutorado em Teoria Literária e Literatura Comparada) - FFLCH - USP, 2007.

FREYRE, G. Casa-grande \& senzala: introdução à história da sociedade patriarcal no Brasil. Rio de Janeiro: Record, 2000.

. (org.). Livro do Nordeste. Recife: Arquivo Público Estadual de Pernambuco, 1975. [Edição fac-similar do livro original, de 1925].

. Manifesto regionalista. Recife: FUNDAJ-Ed. Massangana, 1996.

HOMENAGEM a Manuel Bandeira. Rio de Janeiro: Officinas typographicas do Jornal do Commercio, 1936.

INOJOSA, J. O movimento modernista em Pernambuco. Rio de Janeiro: Gráfica Tupi, 1968. v. 1.

. O movimento modernista em Pernambuco. Rio de Janeiro: Gráfica Tupi,1969a. v. 2

. O movimento modernista em Pernambuco. Rio de Janeiro: Gráfica Tupi,1969b. v. 3

KHLEBNIKOV, V. Poemas de Khlebnikov. Niterói: Cromos, 1993.

MORAES, M. A. (org.). Correspondência Mário de Andrade \& Manuel Bandeira. São Paulo: Edusp, 2000.

вымневидитесьодетыми в звери, в ихшкурах,/Рукойопирающимисянавырванныедубы./Вы даруетеединствомеждузмееобразнымдвижением/Хребтавселенной и пляскойкоромысла,/ Выпозволяетепониматьвека, какбыстрогохохотазубы./Моисейчасвещеобразноразверзлис язеницы/Узнать, чтобудет Я, когдаделимоеего -единица. 
Leandro Pasini é graduado, Mestre e Doutor em Letras (Teoria Literária e Literatura Comparada) pela Universidade de São Paulo (USP). É professor de Literatura Brasileira na Universidade Federal de São Paulo (UNIFESP) e autor do livro $A$ apreensão do desconcerto: subjetividade e nação na poesia de Mário de Andrade (Sáo Paulo: Nankin, 2013). E-mail: leandro.pasini@unifesp.br

Recebido em: 06/02/2018

Aceito em: 30/07/2018 